\title{
ISOLATED PRIMARY CHYLOPERICARDIUM: TREATMENT BY THORACOSCOPIC THORACIC DUCT LIGATION AND PERICARDIAL FENESTRATION
}

\author{
M. Furrer, MD, ${ }^{\mathrm{a}}$ M. Hopf, MD, ${ }^{\mathrm{b}}$ and H. B. Ris, MD, ${ }^{\mathrm{a}}$ Berne, Switzerland
}

Isolated chylopericardium is an uncommon entity. ${ }^{1,2}$ It may be congenital in origin or caused by surgical trauma, irradiation, caval obstruction, or primary or metastatic mediastinal tumors. ${ }^{2,3}$ The sequel common to all origins seems to be thoracic duct obstruction without development of collateral drainage. The exact cause of the disorder in the idiopathic cases is, however, unknown. ${ }^{1}$ The diagnosis is confirmed by analysis of pericardial fluid obtained through pericardiocentesis. Current therapeutic options include dietary treatment, serial pericardiocentesis, pericardial-peritoneal shunts, pericardiectomy, and thoracic duct ligation. $1,2,4$

We report the case of a patient with Recklinghausen disease and isolated chylopericardium successfully treated by video-assisted thoracoscopic surgical techniques. To our knowledge, this article reflects the first application of the preferred minimally invasive approach and is the first report of isolated chylopericardium associated with Recklinghausen disease.

A 35-year-old man with a 20-year history of Recklinghausen disease reported recent cough and dyspnea. Chest radiographs showed an enlarged cardiomediastinal silhouette. The presence of pericardial effusion was confirmed echocardiographically. The diagnosis of Recklinghausen disease was initially made on the basis of multiple caféau-lait skin spots and cutaneous neurofibromatosis located at the right foot and on the left side of the face. There was no evidence of intrathoracic lesions on either chest radiography or computed tomographic scan (Fig. 1). Echocardiographically guided pericardiocentesis produced $800 \mathrm{ml}$ milky fluid, considered to be chyle because of a triglyceride level of $21.4 \mathrm{mmol} / \mathrm{L}$ and typical extracellular fat droplets seen on cytologic examination. The fluid reaccumulated within 14 days, resulting in clinical and echocardiographic signs of tamponade.

Examination of the right thorax by video-assisted thoracoscopic surgical techniques (four trocar sleeves 7 to $10 \mathrm{~mm}$ in diameter inserted between the fifth and tenth intercostal space) revealed a normal pleural cavity without effusion or any signs of intrathoracic neurofibromatotic manifestation. The pericardium appeared to be distended. After the right

From the Department of Thoracic and Cardiovascular Surgery, Inselspital, University of Berne, ${ }^{a}$ and the Division of Cardiology, Beau-Site Hospital, ${ }^{\text {b }}$ Berne, Switzerland.

Received for publication Jan. 9, 1996; accepted for publication Feb. 15, 1996.

J Thorac Cardiovasc Surg 1996;112:1120-1

Copyright $(\mathcal{C} 1996$ by Mosby-Year Book, Inc.

$0022-5223 / 96 \$ 5.00+0 \quad \mathbf{1 2 / 5 4 / 7 2 8 9 2}$ lower lobe was mobilized by transection of the pulmonary ligament, the esophagus, aorta, and right anterior wall of the spine were visualized immediately above the diaphragm. The tissue between these three structures was surrounded and ligated endoscopically. Partial pericardiectomy was performed releasing $1500 \mathrm{ml}$ chylous fluid. The inner surface of the right side of the pericardial sac was carefully explored and assessed as normal.

Histopathologic examination of the excised pericardium revealed minimal fibrous pericarditis and showed no signs of neurofibromatosis. The postoperative course was uneventful. Minimal bilateral pleural effusion disappeared within the first weeks, and follow-up echocardiography suggested only minimal loculated residual effusion 1 month after the surgical intervention.

Tumor-related obstruction of the thoracic duct leading to chylopericardium is most commonly caused by lymphatic hamartomas or lymphangiomas. ${ }^{3}$ Lymphangiectasis and generalized anomalies of the lymphatic system, as suggested by associated lymphocytosis, are also considered to be important etiologic factors. 3,5

In our patient, mediastinal abnormalities could be found neither on computed tomography, nor during careful thoracoscopic exploration of the pleural and pericardial space, nor on histopathologic examination of the excised pericardium. Lymphangiography was not performed. We are unaware of previous reports of primary chylopericardium associated with Recklinghausen disease. One report describes chylous pericardial effusion associated with the Jaffe-Campanacci syndrome, a syndrome related to Recklinghausen disease and characterized by multiple café-au-lait spots and nonossifying fibromata of the bones. ${ }^{6}$ Fibromatotic lesions in the mediastinum not radiologically or thoracoscopically detectible may have caused obstruction of the thoracic duct.

After establishment of the diagnosis of chylopericardium, the treatment of choice for all patients with symptoms is surgical exploration, with thoracic duct ligation and partial pericardiectomy. ${ }^{1,2}$ The most favorable site for ligation is immediately above the diaphragm. Because of wide anatomic variations in the duct in this region, "mass ligature" is recommended. 7,8 This surgical procedure was performed in our case by a right-sided videoassisted thoracoscopic surgical approach, in the same manner that it would have been carried out during standard thoracotomy. As demonstrated by this case, thoracoscopic duct ligation and partial pericardiectomy is a successful technique in the treatment of primary massive chylopericardium.

We gratefully acknowledge Robert J. Downey, MD, for review of the manuscript. 
Volume 112, Number 4

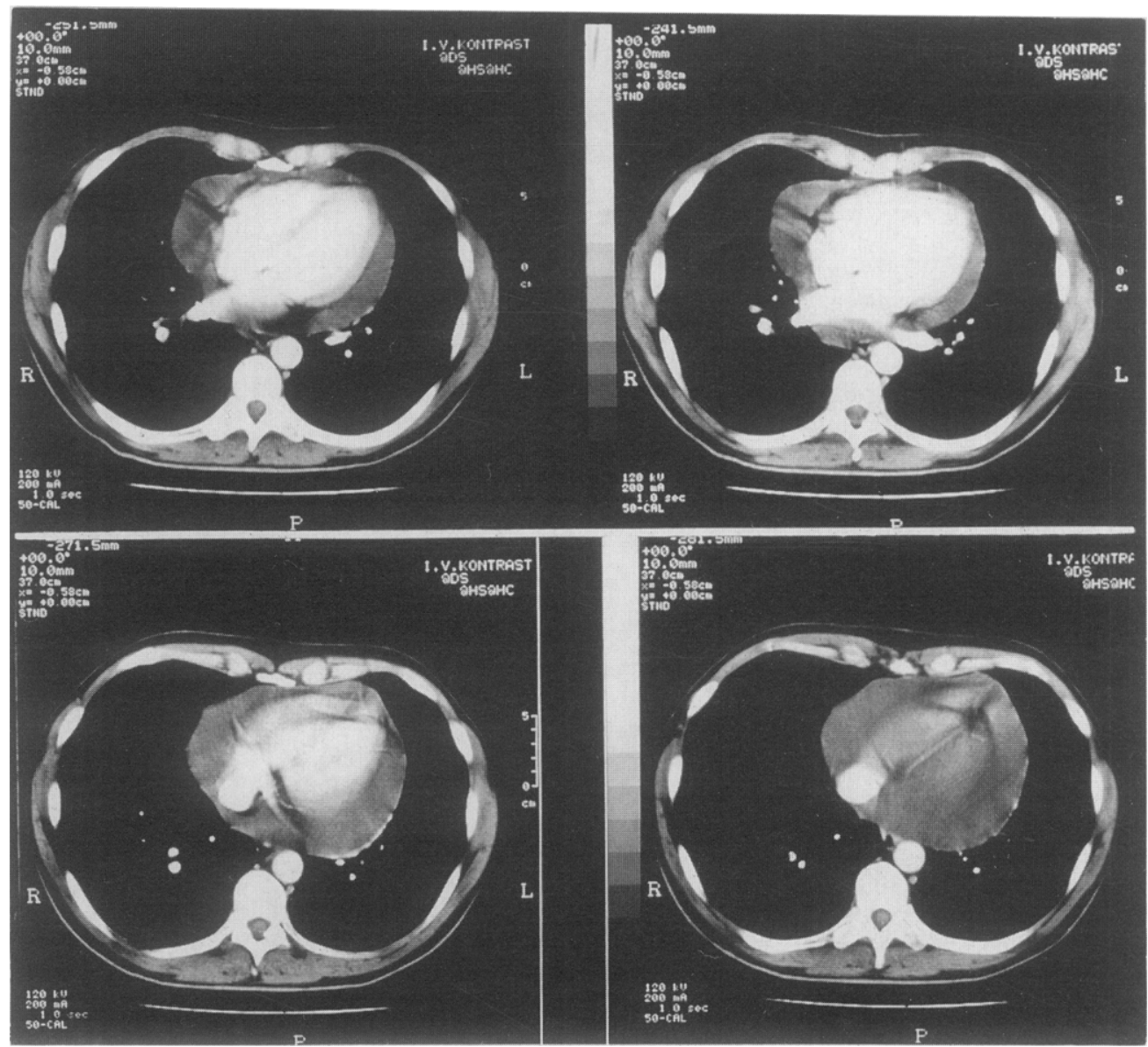

Fig. 1. Thoracic computed tomographic scan shows pericardial effusion but no evidence of intrathoracic neurofibromatosis.

\section{REFERENCES}

1. Dunn RP. Primary chylopericardium: a review of the literature and an illustrated case. Am Heart J 1975;89:369-77.

2. Chan BB, Murphy MC, Rodgers BM. Management of chylopericardium. J Pediatr Surg 1990;25:1185-9.

3. Manetti A, De Simone L, Pollini I, Cecchi F, Tucci F, Dolara A. Linfoangiomatosi generalizzata con chilopericardio. Pediatr Med Chir 1994;16:81-3.

4. Harada K, Takigawa $\mathrm{I}$, Toyoda $\mathrm{H}$, Okada T, Usami $\mathrm{H}$. Primary chylopericardium recovered without surgical treatment: report of a case and review of the literature. Jpn Circ J 1982;46:162-71.
5. Itoh T, Tanaka S, Nakanishi M, Nishiyama K, Kitajima N, Kinoshita $\mathrm{Y}$, et al. Primary chylopericardium with pulmonary shadow and large granular lymphocytosis: a case report. Lymphology 1991;24:168-73.

6. Kotzot D, Stöss H, Wagner H, Ulmer R. Jaffe-Campanacci syndrome: case report and review of literature. Clin Dysmorphol 1994;3:328-34.

7. Gao CX. Surgical management of chylothorax: a report of 65 cases. Chung Hua Wai Ko Tsa Chih 1989;27:164-5, 189.

8. Gallant TE, Hunziker RJ, Gibson TC. Primaty chylopericardium: the role of lymphangiography. Am J Roentgenol 1977; 129:1043-5. 